\title{
Rules for Distinguishing Toxicants That Cause Type I and Type II Narcosis Syndromes
}

\author{
by Gilman D. Veith and Steven J. Broderius*
}

\begin{abstract}
Narcosis is a nonspecific reversible state of arrested activity of protoplasmic structures caused by a wide variety of organic chemicals. The vast majority of industrial organic chemicals can be characterized by a baseline structure-toxicity relationship as developed for diverse aquatic organisms, using only the $n$ octanol/water partition coefficient as a descriptor. There are, however, many apparent narcotic chemicals that are more toxic than baseline narcosis predicts. Some of these chemicals have been distinguished as polar narcotics. Joint toxic theory and isobole diagrams were used to show that chemicals strictly additive with phenol were generally more toxic than predicted by narcosis I models and characterized by a different mode of action called narcosis II syndrome. This type of toxicity is exemplified by certain amides, amines, phenols, and nitrogen heterocycles. Evidence is provided that suggests that narcosis II syndrome may result from the presence of a strong hydrogen bonding group on the molecule, and narcosis I syndrome results from hydrophobic bonding of the chemical to enzymes and/or membranes. This shift in toxic action is apparently indistinguishable for narcotic chemicals with $\log \mathbf{P}$ greater than about 2.7. General rules for selecting the appropriate models are proposed.
\end{abstract}

\section{Introduction}

Narcosis is a reversible state of arrested activity of protoplasmic structures caused by a wide variety of organic chemicals. Veith et al. (1) demonstrated that this nonspecific mode of action was responsible for lethality in the fathead minnow (Pimephales promelas) for many alcohols, ketones, ethers, alkyl halides, and benzene derivatives. The structure-toxicity relationships developed by both Konemann (2) and Veith et al. (1) are very similar and accurately estimate the $\mathrm{LC}_{50}$ of nonreactive, nonpolar chemicals for a wide variety of aquatic organisms (3) using only the $n$-octanol/water partition coefficient $(\log P)$. The equations presented $(1,2)$ have become known as baseline toxicity models that predict the toxicity of chemicals that act through the nonspecific mechanism of narcosis. In general, more specific mechanisms produce greater toxicity than baseline narcosis.

We are attempting to develop structure-toxicity relationships for other mechanisms of lethality and to determine the structural requirements of the chemicals that act through a given mechanism. Since detailed mechanistic studies for all chemicals are not possible, we have clustered chemicals using fish acute toxicity syn-

*U.S. Environmental Protection Agency, Environmental Research Laboratory-Duluth, 6201 Congdon Boulevard, Duluth, MN 55804.

Address reprint requests to G. Veith, U.S. Environmental Protection Agency, Environmental Research Laboratory-Duluth, 6201 Congdon Boulevard, Duluth, MN 55804. dromes (FATS) (4) based on physiological and behavioral symptoms during the test. Baseline narcosis is characterized by progressive lethargy, unconsciousness, and death without any specific sustained symptoms such as hyperventilation, erratic or convulsive swimming, or hemorrhage. Despite the fact that the vast majority of nonreactive industrial chemicals produce symptoms of baseline narcosis, we found many apparent narcotic chemicals to be substantially more toxic than our initial baseline narcotic structure-toxicity relationship predicts.

Ferguson (5) distinguished the more toxic narcotics as polar narcotics because these chemicals were more soluble in water. Ljublina and Filov (6) also distinguished the more toxic narcotics on a basis of greater water solubility. Kamlet et al. (7) recently showed that the increased toxicity of these narcotics was correlated with greater dipolarity and/or hydrogen bond donor acidity of these structures. Kamlet et al. (7) proposed that, if the mechanisms underlying these two narcosis syndromes were the same, a single uniform structure-toxicity relationship for narcosis could be used to predict lethality. Using the FATS methodology mentioned above, however, the toxic responses of nonpolar and polar (aniline and phenol derivatives) narcotics are clearly distinguishable (8).

Franks and Lieb $(9,10)$ provide convincing arguments that the depression of activity by general anesthetics occurs through competitive inhibition of key target enzymes. Hydrophobic binding in pockets of specific en- 
zymes in the central nervous system (yet to be identified) has been proposed as the most likely mechanism leading to inhibition by nonpolar narcotics. Broderius and Kahl (11) used joint toxicity theory and isobole diagrams to show that nonpolar narcotics are strictly additive when tested as mixtures. The condition of strict additivity is necessary for the mechanism to be considered similar for different chemicals. In this paper, we review the evidence for dissimilarity of the underlying mechanisms of nonpolar and polar narcosis. We have defined polar narcosis as the narcosis II syndrome and proposed a structure-toxicity relationship for the narcosis II toxicants (12).

\section{Materials and Methods}

This work extends the use of joint toxicity tests to discriminate between narcosis I and narcosis II chemicals. Toxicity tests were conducted according to standard procedures (13) and have been described in detail previously (11). Briefly, juvenile fathead minnows ( $P i$ mephales promelas) were placed in continuous-flow diluters having five treatment concentrations and a control for each test. Mortalities were recorded daily, and the estimated median lethal concentration $\left(\mathrm{LC}_{50}\right)$ was determined after $96 \mathrm{hr}$. Binary mixtures of chemicals were tested at ratios of 5:0, 4:1, 2:1, 1:1, 1:2, 1:4, and $0: 5$. The $96-\mathrm{hr} \mathrm{LC}_{50} \mathrm{~s}$ of these binary mixtures were used to construct isoboles $(14,15)$ of joint toxic action (Fig. 1). The procedures used to analyze results by concentration or response addition models are those proposed by Finney (17) and Anderson and Weber (18).

The original work of Veith et al. (1) used linear aliphatic alcohols as model nonpolar narcotics, or narcosis

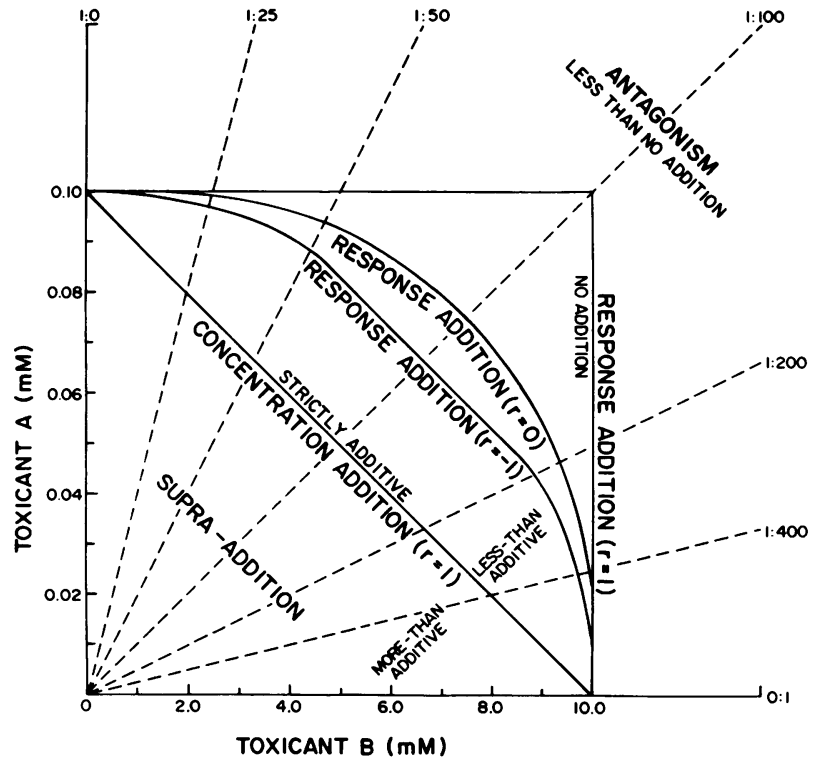

FIGURE 1. Isobole diagram depicting various types of lethal responses for the joint action of two toxicants displaying parallel concentration-response curves. After Muska and Weber (16).
I toxicants. Broderius and Kahl (11) demonstrated the use of $n$-octanol as a reference narcosis I toxicant to test for strict additivity with other toxicants. It was proposed that chemicals which were strictly additive with octanol could be considered narcosis I chemicals and were accurately modeled by the QSARs of Konemann (2) and Veith et al. (1). For this study, we selected phenol as a reference narcosis II toxicant for all joint toxicity tests. The symptoms of fish exposed to phenol are consistent with narcosis II (8) and the toxicity is generally greater than predicted by the narcosis I model.

\section{Results and Discussion}

The toxicity of some amides, amines, phenols, and nitrogen heterocycles are underestimated by the baseline narcosis QSAR presented by Veith et al. (1). Assuming that this QSAR is the narcosis I syndrome, we proposed that these polar chemicals produce narcosis through a different mode of action which we call the narcosis II syndrome. We determined that phenol or aniline are not strictly additive in their joint toxic response with octanol, our reference narcosis I chemical. These results clearly suggest a second mechanism. We tested more than 50 polar chemicals for strict additivity with phenol. Compounds that demonstrate strict additivity with phenol are presented in Table 1, together with the toxicity of the chemicals. Table 1 shows that a wide variety of substituted phenols and primary amines are strictly additive with phenol. This evidence strongly supports the use of a separate structure-toxicity relationship for these polar chemicals.

The joint toxicity studies revealed several important factors with respect to the structural requirements of narcosis II. Five of the phenols and three anilines were strictly additive with both octanol and phenol (Table 1). All of these chemicals except ethylaniline have $\log P$ values greater than 2.7 , whereas those not additive have $\log P$ values less than 2.7. Two compounds with $\log P$ greater than 2.7, 1-naphthol and 4-chloro-3-methylphenol, were not tested in combination with 1-octanol. These data are consistent with the concept that the narcosis II syndrome may result from the presence of a strong hydrogen bonding group on the molecule and the narcosis I syndrome results from hydrophobic bonding of the chemical to enzymes and/or membranes. As the $\log \mathrm{P}$ of the chemicals increases, the relative contribution of hydrogen bonding to the toxicity seemingly decreases in favour of the hydrophobic bonding of the toxicant. For narcotic chemicals with a $\log P$ of 2.7 or greater, it appears that the influence of hydrophobic bonding is equal to or greater than hydrogen bonding. Not only would either QSAR model estimate the toxicity equally well for these lipophilic chemicals, but also the underlying mechanisms of enzyme inhibition is seemingly indistinguishable.

We have noted that all of the chemicals in Table 1 are weakly acidic or basic. Strongly acidic phenols and cer- 
Table 1. Chemicals with strictly additive joint toxicity with phenol.

\begin{tabular}{|c|c|c|c|}
\hline Compound & $\mathrm{CAS}^{\mathrm{a}}$ number & $\begin{array}{l}\log M \\
\text { 96-hr LC } \\
\end{array}$ & $\log P^{b}$ \\
\hline \multicolumn{4}{|l|}{ Amides } \\
\hline 4-Nitrobenzamide & $619-80-7$ & -3.10 & $0.82(\mathrm{~m})$ \\
\hline \multicolumn{4}{|l|}{ Primary aliphatic amines } \\
\hline 1,2-Diaminopropane & $78-90-0$ & -1.77 & -0.91 \\
\hline \multicolumn{4}{|l|}{ Primary aromatic amines } \\
\hline Aniline & $62-53-3$ & -2.84 & $0.90(\mathrm{~m})$ \\
\hline 4-Nitroaniline & $100-01-6$ & -3.04 & 1.31 \\
\hline 4-Chloroaniline & $106-47-8$ & -3.59 & $1.83(\mathrm{~m})$ \\
\hline 2-Chloroaniline & 95-51-2 & -4.35 & $1.90(\mathrm{~m})$ \\
\hline 4-Ethylaniline $\mathrm{c}^{\mathrm{c}}$ & $589-16-2$ & -3.22 & $1.96(\mathrm{~m})$ \\
\hline 2-Chloro-4-nitroaniline & $121-87-9$ & -3.93 & 2.17 \\
\hline 4-Bromoaniline & $106-40-1$ & -3.56 & $2.26(\mathrm{~m})$ \\
\hline 2-Chloro-4-methylaniline & $615-65-6$ & -3.59 & 2.58 \\
\hline 3,4-Dichloroaniline ${ }^{c}$ & $95-76-1$ & -4.33 & $2.69(\mathrm{~m})$ \\
\hline 2,3,4-Trichloroaniline ${ }^{c}$ & $634-67-3$ & -4.73 & $3.33(\mathrm{~m})$ \\
\hline \multicolumn{4}{|l|}{ Substituted phenols } \\
\hline Catechol & $120-80-9$ & -4.08 & 0.81 \\
\hline 4-Amino-2-nitrophenol & $119-34-6$ & -3.63 & 0.96 \\
\hline Phenol & $108-95-2$ & -3.59 & $1.46(\mathrm{~m})$ \\
\hline 3-Methoxyphenol & $150-19-6$ & -3.22 & $1.58(\mathrm{~m})$ \\
\hline 4-Nitrophenol & $100-02-7$ & $-3.53^{\mathrm{d}}$ & $1.91(\mathrm{~m})$ \\
\hline 2,4-Dimethylphenol & $105-67-9$ & $-3.87^{\mathrm{d}}$ & $2.30(\mathrm{~m})$ \\
\hline 4-Ethylphenol & $123-07-9$ & -4.07 & $2.58(\mathrm{~m})$ \\
\hline 1-Naphthol & $90-15-3$ & -4.49 & $2.84(\mathrm{~m})$ \\
\hline 4-Propylphenol ${ }^{\mathrm{c}}$ & $645-56-7$ & -4.09 & 3.18 \\
\hline 2-Phenylphenol ${ }^{\mathrm{c}}$ & $90-43-7$ & -4.44 & 3.36 \\
\hline$p$-Phenoxyphenol ${ }^{\mathrm{c}}$ & $831-82-3$ & -4.58 & 3.75 \\
\hline$p$-tert-pentylphenol ${ }^{\mathrm{c}}$ & $80-46-6$ & -4.80 & 3.98 \\
\hline \multicolumn{4}{|l|}{ Halogenated phenols } \\
\hline 2-Chlorophenol & $95-57-8$ & -4.14 & $2.15(\mathrm{~m})$ \\
\hline 2,4-Dichlorophenol ${ }^{\mathrm{c}}$ & $120-83-2$ & $-4.32^{d}$ & $2.92(\mathrm{~m})$ \\
\hline 4-Chloro-3-methylphenol & $59-50-7$ & -4.40 & $3.10(\mathrm{~m})$ \\
\hline \multicolumn{4}{|l|}{ Pyridines } \\
\hline 4-Acetylpyridine & $1122-54-9$ & -2.86 & $0.48(\mathrm{~m})$ \\
\hline 2-Cyanopyridine & $100-70-9$ & -2.16 & $0.50(\mathrm{~m})$ \\
\hline Pyridine & $110-86-1$ & -2.90 & $0.65(\mathrm{~m})$ \\
\hline 6-Chloro-2-pyridinol & $16879-02-0$ & -2.78 & 1.78 \\
\hline
\end{tabular}

${ }^{\mathrm{a}}$ Chemical Abstract Service registry number.

${ }^{b}$ Computer calculated by CLOGP version 3.4 software or a measured value (m) retrieved from STARLIST (23).

${ }^{c}$ Chemicals also strictly additive with octanol.

${ }^{d}$ From Holcombe et al. (24).

tain anilines are much more toxic than either the narcosis I or narcosis II QSAR would predict, and the toxicity syndrome is clearly not that of narcosis. Rules for discriminating these compounds must be consistent for differentiating an additional toxicity mechanism. Chemicals that do not elicit the narcosis II syndrome and are less than strictly additive with phenol and octanol include phenols or anilines with two or more nitro substituents, or four or more ring substituted halogens. These are more toxic than is estimated from narcosis QSAR models and are likely oxidative phosphorylase uncouplers. This mechanism and associated QSAR will be discussed elsewhere.

The overall results are summarized in Figures 2 through 4. Figure 2 presents the variation in toxicity of narcosis I chemicals with $\log \mathrm{P}$ from three reference systems. These data establish the narcosis I structuretoxicity relationship. Figure 3 presents a group of narcosis II chemicals that are strictly additive with phenol but not octanol. The line for the narcosis II structure- toxicity relationship is summarized by Veith and Broderius (12) as follows:

$$
\begin{aligned}
\log \mathrm{LC}_{50} & =-0.65( \pm 0.07) \log \mathrm{P}-2.29( \pm 0.22) \\
n & =39, \mathrm{r}^{2}=0.90
\end{aligned}
$$

The chemicals that are strictly additive with octanol and phenol are presented in Figure 4.

\section{Summary of Narcosis Selection Rules}

Narcosis is thought to be a reversible and rather nonspecific mode of toxic action. Careful examination of the different symptoms caused by a wide variety of narcotic chemicals suggests the possibility that there are numerous mechanisms of narcosis. Creating structure-toxicity relationships for each may be impossible; nonetheless, we can establish QSARs for major groups and then develop general rules for selecting the appropriate model. 


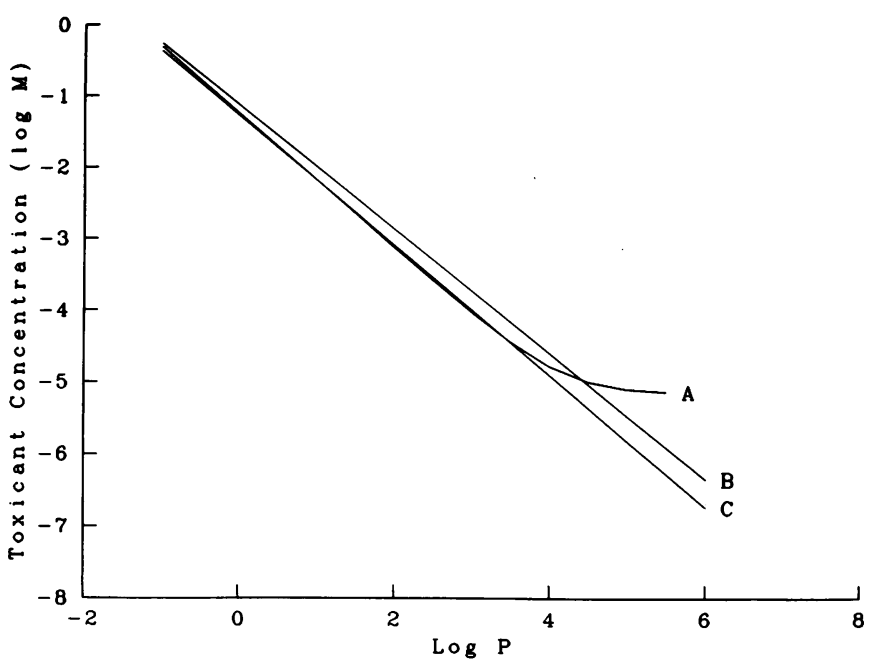

FIGURE 2. Acute toxicity QSAR model regression lines for narcosis I industrial organic chemicals as determined by $(A)$ Veith et al. (1) for the fathead minnow (96-hr LC $\left.\mathrm{LC}_{50}\right) ;(B)$ Konemann (2) for the guppy (7- or 14-day $\mathrm{LC}_{50}$ ); and $(C)$ Hermens et al. (19) for Daphnia magna $\left(48-\mathrm{hr} \mathrm{IC}_{50}\right)$.

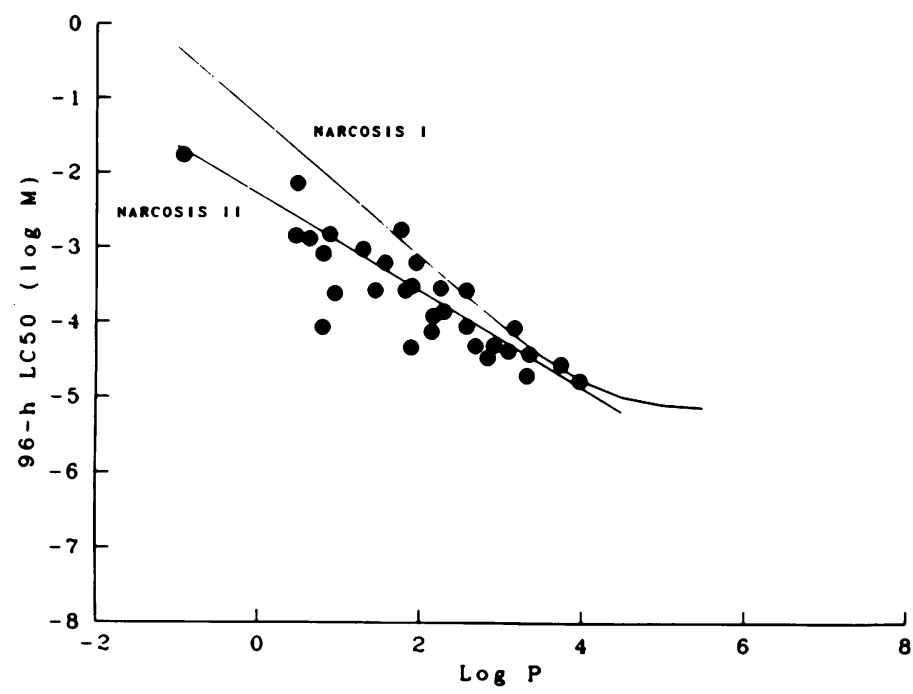

FIgURE 3. Acute toxicity to juvenile fathead minnows of chemicals that are strictly additive in their joint toxicity with phenol. Narcosis I and II model lines are from Veith et al. (1) and Veith and Broderius (12), respectively.

First, the nonspecific nature of narcosis means that chemicals that meet the structural requirements of specific modes of action should be excluded from narcosis QSARs. Narcosis is appropriate only for nonreactive toxicants. Excluded are chemicals which irreversibly bind to natural products through electrophilic reactions (20), are metabolically activated to electrophiles, chemicals such as aldehydes which can form Schiff-bases with amino groups, and Michael-type acceptors.

Kamlet et al. (21) found that amines and carboxylic acids that are strong proton-transfer acids and bases do not conform to narcosis models of nonelectrolytes. We have found that the aquatic toxicity of many alkyl amines and tertiary anilines can be estimated using the

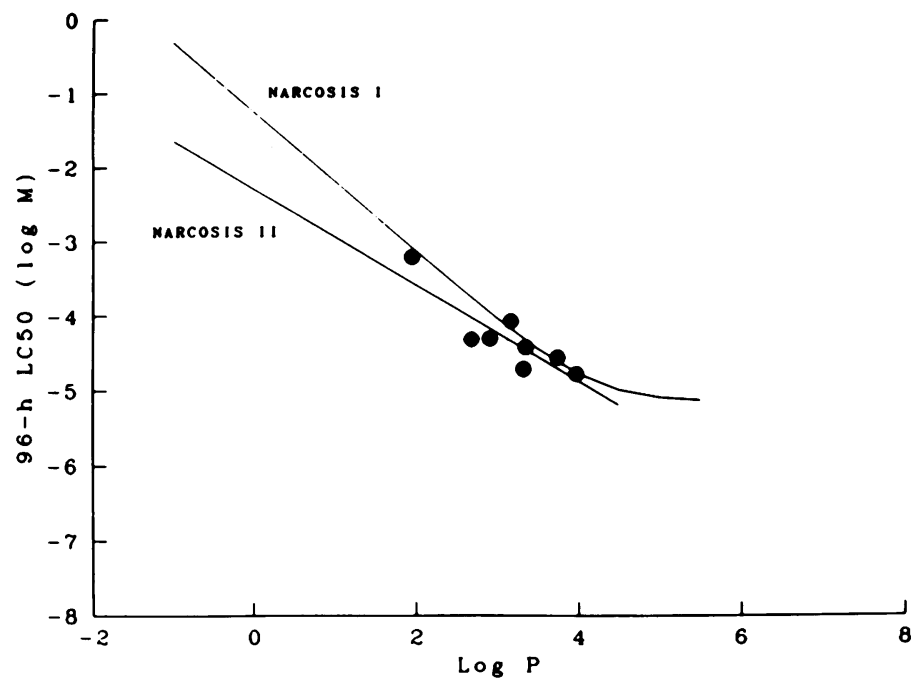

FIGURE 4. Acute toxicity to juvenile fathead minnows of chemicals that are strictly additive in their joint toxicity with either 1-octanol or phenol. Narcosis I and II model lines are from Veith et al. (1) and Veith and Broderius (12), respectively.

narcosis I QSAR. The toxicity of these chemicals is not additive with phenol. Substituents on the nitrogen of amines decrease the polarity of the chemicals and shift the toxicity syndrome from narcosis II to narcosis I.

Carboxylic esters have presented a special problem in the development of structure-activity relations. The literature is replete with examples of anomalous behavior of esters. Kamlet et al. (21) excluded esters from QSARs for narcosis because they rationalized that esters were subject to in vivo hydrolysis. The increase in toxicity of esters over narcosis I chemicals is consistent with and correlated to the alkaline hydrolysis rate constant in water, even though hydrolysis is likely to be a detoxification mechanism. Veith et al. (22) reported that esters have similar symptoms to narcosis I chemicals but are more toxic. The QSAR reported for esters was

$$
\begin{aligned}
\log \mathrm{LC}_{50} & =-0.535 \log \mathrm{P}-2.75 \\
n & =29, \mathrm{r}^{2}=0.828
\end{aligned}
$$

which is nearly identical to the narcosis II QSAR presented earlier. However, in joint action studies, monoesters were strictly additive with octanol, which suggests that the narcosis I QSAR might be improved by including the dipolarity/polarizability term, $\pi^{*}$, proposed by Kamlet et al. (21) to account for increased toxicity. Diesters were found to be less than additive with both octanol and phenol and their toxicity is generally greater than that estimated from the narcosis I QSAR. Until the underlying mechanism of ester toxicity is understood, we recommend using the QSAR for ester narcosis.

\section{REFERENCES}

1. Veith, G. D., Call, D., and Brooke, L. Structure-toxicity relationships for the fathead minnow, Pimephales promelas: narcotic industrial chemicals. Can. J. Fish. Aquat. Sci. 40: 743-748 (1983). 
2. Konemann, H. Quantitative structure-activity relationships in fish toxicity studies. I. Relationship for 50 industrial pollutants. Toxicology 19: 209-221 (1981).

3. Thurston, R. V., Gilfoil, T. A., Meyn, E. L., Zajdel, R. K., Aoki, T. I., and Veith, G. D. Comparative toxicity of ten organic chem icals to ten common aquatic species. Water Res. 19: 1145-1155 (1985).

4. McKim, J. M., Bradbury, S. P., and Niemi, G. J. Fish acute toxicity syndromes and their use in the QSAR approach to hazard assessment. Environ. Health Perspect. 71: 171-186 (1987).

5. Ferguson, J. The use of chemical potentials as indices of toxicity. Proc. Roy. Soc. London. Ser. B. 127: 387-404 (1939).

6. Ljublina, E. I., and Filov, V. A. Chemical structure, physical and chemical properties, and biological activity. In: Methods Used in the U.S.S.R. for Establishing Biologically Safe Levels of Toxic Substances. World Health Organization, Geneva, 1975.

7. Kamlet, M. J., Doherty, R. M., Veith, G. D., Taft, R. W., and Abraham, M. H. Solubility properties in polymers and biological media. 7. An analysis of toxicant properties that influence inhibition of bioluminescence in Photobacterium phosphoreum (The Microtox Test). Environ. Sci. Technol. 20: 690-695 (1986).

8. Bradbury, S. P., Henry, T. R., Niemi, G. J., Carlson, R. W., and Snarski, V. M. Use of respiratory-cardiovascular responses of rainbow trout (Salmo gairdneri) in identifying acute toxicity syndromes in fish. Part 3: Polar narcotics. Environ. Toxicol. Chem. 8: 247-261 (1989).

9. Franks, N. P., and Lieb, W. R. Do general anaesthetics act by competitive binding to specific receptors? Nature 310: 599-601 (1984).

10. Franks, N. P., and Lieb, W. R. Mechanisms of general anesthesia. Environ. Health Perspect. 87: 199-205 (1990).

11. Broderius, S. J., and Kahl, M. Acute toxicity of organic chemical mixtures to the fathead minnow. Aquat. Toxicol. 6: 307-322 (1985).

12. Veith, G. D., and Broderius, S. J. Structure-toxicity relationships for industrial chemicals causing type (II) Narcosis syndrome. In QSAR in Environ. Toxicol-II (K. L. E. Kaiser, Ed.), D. Reidel Publishing Co., Dordrecht, Holland, 1987, pp. 385-391.

13. American Society for Testing and Materials. Standard practice for conducting acute toxicity tests with fish, macroinvertebrates, and amphibians. Annual Book of ASTM Standards, American
Society for Testing and Materials, Philadelphia, PA, 1980, pp. 729-780.

14. Loewe, S. The problem of synergism and antagonism of combined drugs. Arzneim.-Forsch. 3: 285-290 (1953).

15. Loewe, S. Die quantitativen probleme der pharmakologie. Ergeb. Physiol. Biol. Chem. Exp. Pharmakol. 27: 47-187 (1928).

16. Muska, C. F., and Weber, L. J. An approach for studying the effects of mixtures of environmental toxicants on whole organism performance. Recent Advances in Fish Toxicology-A Symposium (R. A. Tubb, Ed.), EPA/600/3-77/085, Ecological Research Series, Corvallis Environmental Research Laboratory, Corvallis, OR, 1977, pp. 71-87.

17. Finney, D. J. Probit Analysis, 3rd edition. Cambridge University Press, Cambridge, MA, 1971.

18. Anderson, P. D., and Weber, L. J. The toxicity to aquatic populations of mixtures containing certain heavy metals. Proc. Int. Conf. Heavy Metals Environ. 2: 933-953 (1975).

19. Hermens, J., Canton, H., Janssen, P., and DeJong, R. Quantitative structure-activity relationships and toxicity studies of mixtures of chemicals with anaesthetic potency: Acute lethal and sublethal toxicity to Daphnia magna. Aquat. Toxicol. 5: 143-154 (1984).

20. Hermens, J. L. M. Electrophiles and acute toxicity to fish. Environ. Health Perspect. 87: 219-225 (1990)

21. Kamlet, M. J., Doherty, R. M., Taft, R. W., Abraham, M. H., Veith G. D., and Abraham, D. J. Solubility properties in polymers and biological media. 8. An analysis of the factors that influence toxicities of organic nonelectrolytes to the golden orfe fish (Leuciscus idus melanotus). Environ. Sci. Technol. 21: 149-155 (1987).

22. Veith, G. D., DeFoe, D. L., and M. L. Knuth. Structure-activity relationships for screening organic chemicals for potential ecotoxicity effects. Drug Metab. Rev. 15: 1295-1303 (1984-1985).

23. Leo, A. J., and Weininger, D. Medicinal Chemistry Project, Medchem Software ClogP Version 3.4, Pomona College, Claremont, CA, 1988.

24. Holcombe, G. W., Phipps, G. L., Knuth, M. L., and Felhaber,

- T. The acute toxicity of selected substituted phenols, benzenes and benzoic acid esters to fathead minnows, Pimephales promelas. Environ. Pollut. Ser. A Ecol. Biol. 35: 367-381 (1984). 